\title{
A Single-Center Retrospective Study on the Effects of Korean Medicine in 342 Traffic Accident Cases
}

\author{
Jin-Ho Jeong ${ }^{1}$, Jaseung $\mathrm{Ku}^{2}$, Ji Hye Hwang ${ }^{3}$ * \\ ${ }^{1}$ Jisung-Kyunghee Korean Medicine Clinic, Seoul, Republic of Korea \\ ${ }^{2}$ Bogwang Korean Medical Clinic, Seoul, Republic of Korea \\ ${ }^{3}$ Department of Acupuncture \& Moxibustion Medicine, College of Korean Medicine, Gachon University, Seongnam, Republic of Korea
}

Received May 27, 2021

Reviewed June 7, 2021

Accepted July 20, 2021

* Corresponding Author

Ji Hye Hwang

Department of Acupuncture \&

Moxibustion Medicine, College of Korean

Medicine, Gachon University, Seongnam

13120, Republic of Korea

Tel: +82-32-770-1342

E-mail: jhbori@nate.com
Objectives: In South Korea, traffic accident victims can be treated under automobile insurance coverage. Korean medicine (KM) clinics have reported the largest number of automobile insurance fee claims among medical institutions. This study investigated the status of the KM automobile insurance system in a single KM clinic.

Methods: We retrospectively surveyed the medical charts of 342 traffic accident patients treated at the Jisung KM clinic between January 2009 and June 2017.

Results: Most of the patients were men and in their 30s. The most common method of locating the clinic was an internet search. The most common traffic accident type was collision between vehicles (83.63\%), with $70.76 \%$ of patients visiting during the most acute phase. The major disease codes included S434, M4836, F072, S0600, and S3350. The most frequent treatment period was within 1 month of the accident, and most patients received 10 or fewer treatments. The mean treatment duration and number of treatments were $37.68 \pm 45.11$ days and $11.68 \pm 10.63$ treatments, respectively. The initial pain numerical rating scale (NRS), $7.32 \pm 0.96$, decreased to $3.57 \pm 1.40$ at the end of treatment, with a symptom improvement score of $1.87 \pm 0.60$. Regarding sex, age, disease duration, location at the time of the accident, presence of additional and psychological symptoms, and chuna, there were statistically significant differences in treatment duration and number of treatments. A higher number of treatments and the longer treatment duration was associated with a higher initial NRS, lower post-treatment NRS, and better improvement score. Since the introduction of traffic accident (TA) pharmacopuncture, the rate of use of a single type of pharmacopuncture increased; however, no significant differences in treatment duration and number, NRS before and after treatment, and improvement score were observed between treatment groups before and after TA pharmacopuncture. No adverse reactions were observed for any treatment.

Conclusion: This study confirmed the previous findings of a high treatment effect of KM under automobile insurance. We also observed significant correlations based on a detailed medical status, which may explain the increasing use of KM in the automobile insurance system. Additional multi-center studies in different regions are needed.

Keywords: automobile insurance, traffic accident, korean medicine, acupuncture, pharmacopuncture, retrospective study

\section{INTRODUCTION}

Traffic accident injuries are common and can cause unexpected pain and functional decline [1]. The estimated associated annual costs after road accidents in 2016 exceeded $£ 35$ billion in the United Kingdom and exceeded USD 21 billion in South Korea, accounting for approximately $1.4 \%$ of the gross domestic product $[2,3]$. As traffic accidents cause serious socioeconomic problems worldwide, the management of injuries and aftereffects of traffic accidents has become an important 
issue.

In South Korea, traditional Korean medicine (TKM) techniques, such as acupuncture and herbal medicine, along with chuna manual therapy, pharmacopuncture, and physical therapy are now included in the automobile insurance coverage and are provided to traffic accident patients [4]. According to the Automobile Insurance Statistical Data from the Health Insurance Review \& Assessment Service, TKM automobile insurance medical expenses doubled, from KRW 357.8 billion in 2015 to KRW 713.9 billion in 2018. In addition, a $21 \%$ increase in the number of patients at TKM institutions was reported, compared to a $1 \%$ increase at western medicine (WM) institutions [5].

Traffic accident patients have more mild injuries such as simple sprains and concussions than severe injuries, and most patients complain of neck and back pain [6]. Sprains of the cervical and lumbar spine show no major abnormalities in radiological assessments, and many patients prefer TKM for conservative treatment [7].

In 2018, medical expenses associated with TKM, including at 295 TKM hospitals and 11,582 TKM clinics, increased by $28.76 \%$ year-on-year to KRW 713.9 billion. In particular, TKM clinics accounted for the largest percentage of the 19,650 medical institutions providing automobile insurance and ranked first in the total number of claims and total care costs for automobile insurance [5].

Owing to the rapid growth of the TKM automobile insurance market, data on satisfaction and improvement following TKM treatment have been collected $[6,8]$; however, there are few reports on the status of automobile insurance treatments at TKM clinics [9]. Therefore, additional reports on the medical status at TKM clinics are needed. Thus, this study retrospectively analyzed the current status and effect of automobile insurance TKM treatment in a single TKM clinic and verified the justification for TKM treatment under automobile insurance.

\section{MATERIALS AND METHODS}

\section{Subjects}

This study included 342 of 385 patients who received outpatient treatment at Jisung Kyunghee TKM Clinic for traffic accident injuries between January 1, 2017, and June 30, 2019, except for 43 patients who did not find accurate treatment results. The 43 excluded patients included 26 who received fewer than two treatments, two for whom improvement could not be confirmed in the chart records, two who were treated once in our clinic and in another clinic for several months, four who visited more than 6 months after the accident, eight under 19 years of age, and one who received only four treatments in preparation for pregnancy after abortion. This study was a retrospective review of the charts of patients who provided informed consent and was approved by the Institutional Review Board of Gachon University Korean Medical Hospital (IRB No. M-19-123).

\section{Research method}

The 342 cases were examined for overall medical treatment status according to sex and age, accident type, disease duration, symptoms and diagnosis, and treatment duration and frequency. We analyzed the treatment duration and frequency, pain numerical rating scale (NRS) before and after treatment, and symptom improvement score according to sex and age, accident type, disease duration, additional symptoms and psychological symptoms, and chuna treatment. We also analyzed the status of patients who received pharmacopuncture and investigated the treatment response and adverse events during the treatment period.

\section{Evaluation of treatment grade and symptom improvement}

The pain index used in this study was the NRS. The initial NRS was defined as the most severe pain immediately after the accident, while the late NRS was that at the end of treatment. Subjective symptom improvement was classified into four stages: (1) Excellent (no functional impairment due to normal recovery of subjective symptoms and physical examination), (2) good (subjective symptoms and physical examination showed clear improvement compared to those in the first visit), (3) fair (improvement or slight improvement on subjective symptoms and physical examination), and (4) poor (no improvement or worsened condition on subjective symptoms and physical examination) using Odom's criteria [8-11] and a score of 1-4 points using a Likert four-point scale.

\section{Intervention}

Acupuncture was performed for 15 minutes with disposable stainless needles $(0.25 \mathrm{~mm}$ in diameter and $40 \mathrm{~mm}$ in length, Dong Bang, Boryeong, Korea) at a depth of 10-30 mm, depend- 
ing on the insertion site. The acupoints were mainly the GB20, GV17, GB21, GV4, GV3, BL23, GV30, and ouch points (ashi points). According to the patient's symptoms, electro-acupuncture stimulation, cupping, pharmacopuncture, and chuna manual therapy were combined. In cases requiring drug treatment, concussion symptoms were first treated with a concussion prescription, which is a combination of Dohongsamultang and BanhabaekchulcheonMatang; in addition, Hwaeojeon-gami prescription was used for trauma blood stasis. Physiotherapy was performed once daily, mainly using interferential current therapy and a hot pack according to the patient's condition.

\section{Safety and adverse reactions to treatment}

Immediately after each treatment and at the next visit, we checked for bleeding, hematoma, fatigue, sweating, severe nausea, dizziness, and headache, as well as infections and patient discomfort related to treatments such as acupuncture, pharmacopuncture, herbal medicine, and chuna treatment.

\section{Statistical analysis}

The statistical analyses were performed using IBM SPSS Statistics for Windows, version 25.0. Relationships between the treatment period and number, NRS before and after treatment, and symptom improvement for each factor were assessed by independent two-sample t-tests for two groups and one-way analysis of variance (ANOVA) for three or more groups. The correlations between the treatment duration, number of treatments, NRS before and after treatment, and improvement were

Table 1. Patient characteristics

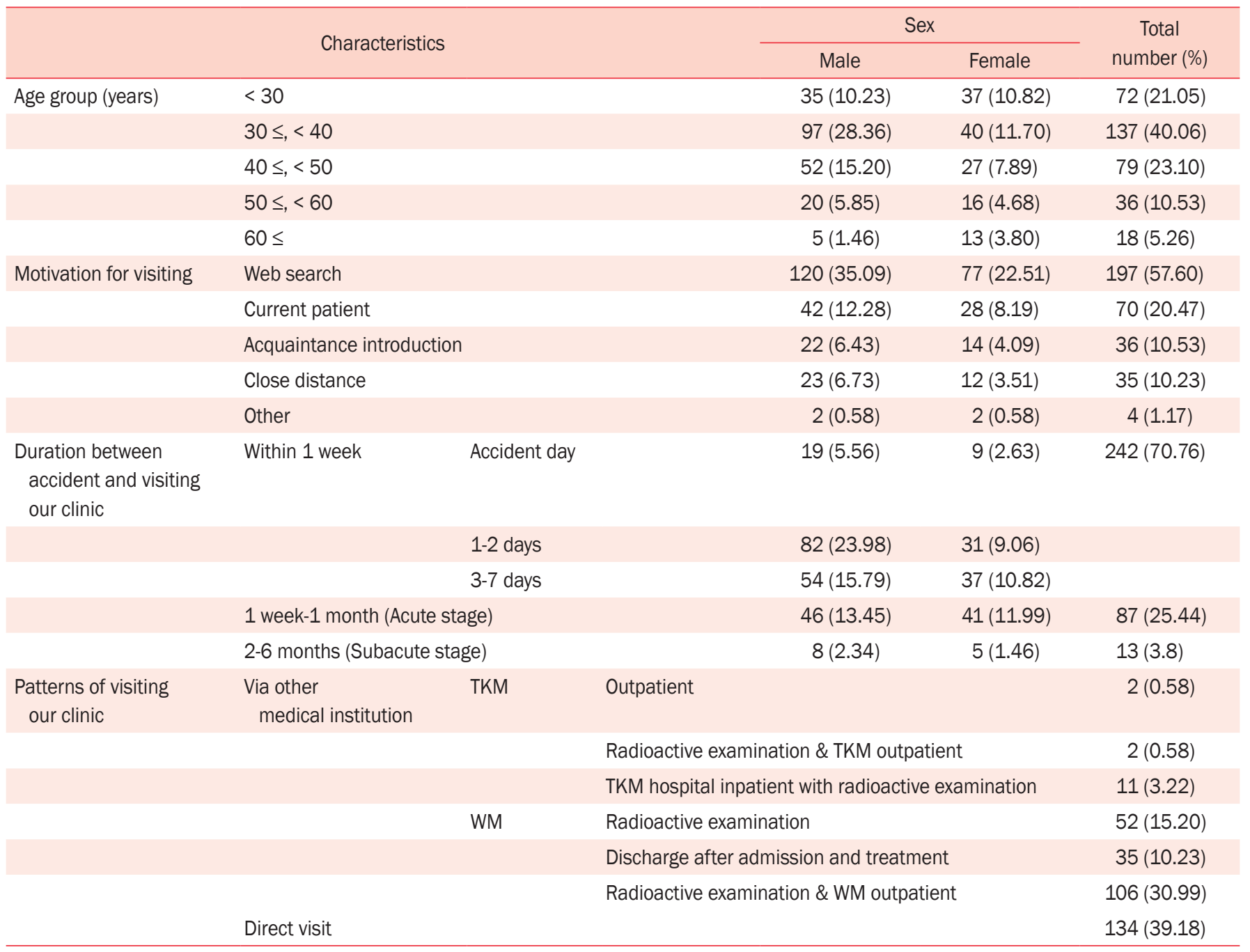

TKM, traditional Korean medicine; WM, Western medicine. 
evaluated by Pearson's correlation analysis. $\mathrm{p}<0.05$ was considered statistically significant.

\section{RESULTS}

1. Distribution by sex, age, visit motivation, and disease duration

The study population was composed of 1.51 times more men $(\mathrm{n}=209,61.11 \%)$ than women $(\mathrm{n}=138,38.99 \%)$. The age distribution was as follows: individuals in their $20 \mathrm{~s}(\mathrm{n}=72$, 21.05\%), 30s ( $\mathrm{n}=137,40.06 \%), 40 \mathrm{~s}(\mathrm{n}=79,23.10 \%), 50 \mathrm{~s}(\mathrm{n}=$ $36,10.53 \%)$, and 60 s or older ( $\mathrm{n}=18,5.26 \%)$. The most common motivations for visiting the clinic were an internet search (197 patients, 57.60\%), followed by previous treatment at our clinic (70 patients, $20.47 \%$ ), introduction by acquaintances (36 patients, $10.53 \%$ ), proximity (35 patients, $10.23 \%$ ), and other reasons (4 patients, $1.17 \%)$. Most patients $(242,70.76 \%)$ visited during the most acute phase (within 1 week); 87 patients (25.44\%) visited in the acute phase (1 week-1 month) and 13 patients (3.80\%) visited during the subacute stages (1-6 months after onset) (Table 1).

\section{Distribution of patterns of visiting our clinic}

A total of 134 patients (39.18\%) visited our clinic without visiting other hospitals, while 208 (60.82\%) visited our clinic after visiting another hospital. Among patients who visited WM institutions, 52 (15.20\%) received only physical and radiological examinations without treatment, 35 (10.23\%) visited our clinic after inpatient treatment at WM hospitals, and 106 (30.99\%) visited our clinic after examination and outpatient treatment at WM clinics. Among patients who visited KM institutions, 11 (3.22\%) were hospitalized with radiological examinations and two $(0.58 \%$ each) visited our clinic after visiting another KM clinic with or without radiological examination (Table 1).

\section{Distribution according to traffic accident characteristics}

Among the accident types, 286 cases (83.63\%) were caused by collisions between vehicles. Among them, 218 (63.74\%), 36 (10.53\%), 14 (4.09\%), and 18 (5.26\%) cases were rear, lateral, forward, and multiple collisions, respectively. Furthermore, 23 accidents were between vehicles and pedestrians (6.73\%), 24 were between vehicles and motorcycles (7.02\%), three were be- tween vehicles and bicycles (0.88\%), and six occurred while on a bus (1.75\%). The distribution according to the location at the time of the accident included 257 cases in driver seats (75.15\%), 17 in passenger seats (4.97\%), 12 in back seats (3.51\%), 23 pedestrians (6.73\%), 27 motorcycles or bicycles (7.89\%), and five bus passengers (0.39\%) (Table 2).

\section{Distribution according to symptoms and diagnosis}

The symptoms were divided into physical and psychological symptoms. The major physical symptoms were localized pain in all patients, including 306 (89.47\%) patients with pain in the lumbar and pelvic region, 297 (86.84\%) with pain in the cervical spine and shoulders, 202 (59.06\%) with headaches, 21 (6.14\%) with pain in the knee and ankle, $9(2.63 \%)$ with pain in the wrist and elbow, and $5(1.46 \%)$ with other symptoms. Dizziness, limb numbness, and fatigue were reported in 156 (45.6\%), 78 (22.8\%), and $40(11.7 \%)$ cases, respectively. Other symptoms included tinnitus, jaw joint problems, and digestive problems. The major psychological symptoms were sleep disorders (41 cases, $12.0 \%$ ), chest discomfort (19 cases, 5.7\%), palpitations (16 cases, $4.7 \%$ ), followed by a sign of surprise, memory disorders, emotional control disorders, anxiety, depression, stress, and other symptoms.

Among disease code distributions, duplication of cases with two or more diagnosed cases showed sprain to be the most common, with the major disease codes being S434 (sprain and strain of shoulder joint), M4836 (traumatic spondylopathy, lumbar region), F072 (postconcussional syndrome), S0600 (concussion, without open intracranial wound), and S3350 (sprain and strain of the lumbar spine) (Table 2).

\section{Distribution according to treatment duration and number of treatments}

A total of 218 patients (63.74\%) sought treatment within 1 month, including 57 patients (20.46\%) within 2 weeks, 64 (18.71\%) within 1 month, 44 (12.87\%) within 3 weeks, and 40 (11.70\%) within 1 week. Furthermore, 67 (19.59\%) patients sought treatment within 2 months, 29 (8.48\%) within 3 months, $10(2.92 \%)$ within 4 months, and 18 (5.26\%) after 4 months or more. Most patients $(204,59.65 \%)$ received fewer than 10 treatments; 90 (16.67\%), 27 (7.89\%), and 21 (6.14\%) patients received fewer than 20 , fewer than 30 , and more than 30 treatments, respectively (Table 3). 
Jin-Ho Jeong, et al.

Table 2. Distribution of traffic accident characteristics, symptoms, and disease codes

\begin{tabular}{|c|c|c|c|c|}
\hline \multicolumn{4}{|c|}{ Characteristics } & \multirow{2}{*}{$\begin{array}{c}\text { Total number (\%) } \\
218(63.74)\end{array}$} \\
\hline Traffic accident & Traffic accident patterns & Car to car & Rear impact & \\
\hline & & & Frontal impact & 14 (4.09) \\
\hline & & & Side impact & $36(10.53)$ \\
\hline & & & Multiple impact & $18(5.26)$ \\
\hline & & Pedestrian & & $23(6.73)$ \\
\hline & & Car to motorbike & & $24(7.02)$ \\
\hline & & Car to bicycle & & $3(0.88)$ \\
\hline & & On the bus & & $6(0.39)$ \\
\hline & Location & Driver's seat & & $257(75.15)$ \\
\hline & & Passenger seat & & $17(4.97)$ \\
\hline & & Back seat & & $12(3.51)$ \\
\hline & & Pedestrian & & $23(9.30)$ \\
\hline & & Motorbike, bicycle & & $27(7.89)$ \\
\hline & & Bus & & $6(0.39)$ \\
\hline \multirow[t]{12}{*}{ Symptoms* } & Physical symptoms & Localized pain & Neck \& shoulder & $297(86.84)$ \\
\hline & & & Low back \& buttocks & $306(89.47)$ \\
\hline & & & Head & $202(59.06)$ \\
\hline & & & Knee \& ankle & $21(6.14)$ \\
\hline & & & Elbow \& wrist & $9(2.63)$ \\
\hline & & & Other & $5(1.46)$ \\
\hline & & Limb numbness & & $78(22.8)$ \\
\hline & & Dizziness & & $156(45.6)$ \\
\hline & & Fatigue & & $40(11.7)$ \\
\hline & Psychological symptoms & Sleep disorder & & $41(12.0)$ \\
\hline & & Chest discomfort d & & $19(5.7)$ \\
\hline & & Palpitations & & $16(4.7)$ \\
\hline \multirow[t]{5}{*}{ Disease code* } & \multicolumn{3}{|c|}{ S434: Sprain and strain of the shoulder joint } & $259(75.73)$ \\
\hline & \multicolumn{3}{|c|}{ M4836: Traumatic spondylopathy, lumbar region } & $224(65.50)$ \\
\hline & \multicolumn{3}{|c|}{ F072: Post-concussion syndrome } & $113(33.04)$ \\
\hline & \multicolumn{3}{|c|}{ S0600: Concussion, without an open intracranial wound } & $71(20.76)$ \\
\hline & \multicolumn{3}{|c|}{ S3350: Sprain and strain of the lumbar spine } & $66(19.30)$ \\
\hline
\end{tabular}

*Multiple choices were allowed for 'symptoms' and 'disease code'.

\section{Distribution of treatment methods}

A total of 341 patients (99.71\%) received acupuncture, 251 (73.39\%) were prescribed herbal medicine, 340 (99.42\%) received pharmacopuncture, 298 (87.13\%) received KM physiotherapy, and 153 (44.74\%) received chuna therapy. Among patients receiving pharmacopuncture medicine, 126 (36.84\%), $109(31.87 \%)$, and $105(30.70 \%)$ received one, two, or three or more types of pharmacopuncture. Regarding the types of pharmacopuncture used, when including duplicated pharmacopuncture, there were 180 (52.63\%) cases of TA named after traffic accidents (Scutellaria baicalensis, Phellodendron amurense, Pulsatilla koreana, Sophorae Tonkinensis Radix et Rhizoma, Aucklandia lappa, and Carthamus tinctorius L.), 119 (34.80\%) cases of HO named after Honghwaja (Carthamus tinctorius L), 87 (25.44\%) cases of $\mathrm{CH}$ named after channel and developed to 
Table 3. Distribution of treatment duration, number of treatments, and treatment method

\begin{tabular}{|c|c|c|c|c|}
\hline \multicolumn{4}{|c|}{ Characteristics } & \multirow{2}{*}{$\begin{array}{c}\text { Total number }(\%) \\
40(11.70)\end{array}$} \\
\hline \multirow[t]{8}{*}{ Treatment duration } & $\leq 1$ week & & & \\
\hline & $\leq 2$ weeks & & & $57(20.46)$ \\
\hline & $\leq 3$ weeks & & & $44(12.87)$ \\
\hline & $\leq 1$ month & & & $64(18.71)$ \\
\hline & $\leq 2$ months & & & $67(19.59)$ \\
\hline & $\leq 3$ months & & & $29(8.48)$ \\
\hline & $\leq 4$ months & & & $10(2.92)$ \\
\hline & $\geq 4$ months & & & $18(5.26)$ \\
\hline \multirow[t]{4}{*}{ Number of treatments } & $\leq 10$ & & & $204(59.65)$ \\
\hline & $\leq 20$ & & & $90(16.67)$ \\
\hline & $\leq 30$ & & & $27(7.89)$ \\
\hline & $30<$ & & & $21(6.14)$ \\
\hline \multirow[t]{12}{*}{ Treatment method } & Acupuncture & & & 341 (99.71) \\
\hline & Herbal medicine & & & 251 (73.39) \\
\hline & Pharmacopuncture & $\begin{array}{l}\text { Total pharmacopuncture types } \\
\text { used for treatment }\end{array}$ & 1 & $126(36.84)$ \\
\hline & & & 2 & 109 (31.87) \\
\hline & & & $\geq 3$ & $105(30.70)$ \\
\hline & & Type of pharmacopuncture & TA & $180(58.44)$ \\
\hline & & & $\mathrm{HO}$ & $119(38.64)$ \\
\hline & & & $\mathrm{CH}$ & $87(28.25)$ \\
\hline & & & MOK & $85(27.60)$ \\
\hline & & & Others & $46(13.45)$ \\
\hline & Chuna & & & $153(44.74)$ \\
\hline & TKM physiotherapy & & & $298(87.13)$ \\
\hline
\end{tabular}

TKM, traditional Korean medicine; TA, a pharmacopuncture medicine which was named after traffic accidents and consists of Scutellaria baicalensis, Phellodendron amurense, Pulsatilla koreana, Sophorae Tonkinensis Radix et Rhizoma, Aucklandia lappa, and Carthamus tinctorius L.; HO, a pharmacopuncture medicine which was named after Honghwaja (Carthamus tinctorius L); CH, a pharmacopuncture medicine which was named after channel, developed to control pain using sodium channels by adding salt and consists of Moschus, Ursi Fel, Bovis Calclus, Scutellaria baicalensis, Phellodendron amurense, Pulsatilla koreana, Sophorae Tonkinensis Radix et Rhizoma, Aucklandia lappa, and salt; MOK, a pharmacopuncture medicine which was commonly used to treat clinical symptoms related to heart and thyroid diseases and consists of Moschus, Ursi Fel, Bovis Calclus, Scutellaria baicalensis, Phellodendron amurense, Pulsatilla koreana, Sophorae Tonkinensis Radix et Rhizoma, Aucklandia lappa, and Hominis Placenta.

control pain using sodium channels by adding salt (Moschus, Ursi Fel, Bovis Calclus, Scutellaria baicalensis, Phellodendron amurense, Pulsatilla koreana, Sophorae Tonkinensis Radix et Rhizoma, Aucklandia lappa, and salt), 85 (24.85\%) cases of MOK commonly used to treat clinical symptoms related to heart and thyroid diseases (Moschus, Ursi Fel, Bovis Calclus, Scutellaria baicalensis, Phellodendron amurense, Pulsatilla koreana, Sophorae Tonkinensis Radix et Rhizoma, Aucklandia lappa, and Hominis Placenta), and 46 other pharmacopuncture cases (13.45\%) (Table 3). Pharmacopuncture used was manu- factured at Namsangcheon extramural herbal medicine Dispensary (Yongin, Korea).

\section{Treatment duration and number of treatments, NRS} before and after treatment, and symptom improvement for each characteristic

\section{1) Overall results}

The mean treatment duration and number of treatments for all patients were $37.68 \pm 45.11$ days and $11.68 \pm 10.63$ treat- 
ments, respectively. The initial NRS was $7.32 \pm 0.96$ and decreased to $3.57 \pm 1.40$ at the end of treatment, with a symptom improvement score of $1.87 \pm 0.60$ (Table 4).

\section{2) Results according to sex and age}

The mean treatment duration and number of treatments in men was $32.90 \pm 35.09$ days and $10.62 \pm 9.05$ treatments, respectively. The NRS decreased from $7.27 \pm 0.94$ to $3.53 \pm 1.45$, with an improvement score of $1.84 \pm 0.63$. In women, the mean treatment duration and number of treatments were $45.18 \pm$ 56.92 days and $13.35 \pm 12.62$ treatments, respectively. The NRS decreased from $7.39 \pm 0.98$ to $3.64 \pm 1.30$, with an improvement score of $1.91 \pm 0.55$. Significant differences were observed in treatment duration $(\mathrm{p}<0.01)$ and number of treatments $(\mathrm{p}<$ $0.01)$.

The mean treatment duration and number of treatments in patients less than 30 years of age was $42.92 \pm 60.84$ days and $11.43 \pm 11.92$ treatments, respectively. The NRS decreased from $7.31 \pm 0.97$ to $3.49 \pm 1.45$, with an improvement score of $1.81 \pm$ 0.54 . Among patients in their $30 \mathrm{~s}$, the mean treatment duration and number of treatments were $29.85 \pm 34.29$ days and $9.78 \pm$ 9.14 treatments, respectively. The NRS decreased from $7.25 \pm$ 0.93 to $3.84 \pm 1.43$, with an improvement score of $1.95 \pm 0.61$. Among patients in their 40s, the mean treatment duration and number of treatments were $37.67 \pm 38.87$ days and $11.99 \pm 9.08$ treatments, respectively. The NRS decreased from $7.37 \pm 1.04$ to $3.34 \pm 1.25$, with an improvement score of $1.84 \pm 0.64$. Among patients in their $50 \mathrm{~s}$, the mean treatment duration and number of treatments were $50.25 \pm 47.59$ days and $16.83 \pm 14.28$, respectively. The NRS decreased from $7.44 \pm 0.80$ to $3.21 \pm 1.18$, with an improvement score of $1.72 \pm 0.56$. Among patients in their $60 \mathrm{~s}$ and older, the mean treatment duration and number of treatments were $51.11 \pm 57.85$ days, and $15.44 \pm 10.65$ treatments, respectively. The NRS decreased from $7.42 \pm 0.89$ to $3.61 \pm 1.46$, with an improvement score of $1.94 \pm 0.62$. Significant differences were observed in treatment duration $(\mathrm{p}<0.01)$ and number of treatments $(\mathrm{p}<0.01)$ according to patient age (Table 4$)$.

\section{3) Treatment results according to disease duration}

The mean treatment duration and number of treatments during the most acute phase (within 1 week) was $33.49 \pm 40.23$ days and $11.58 \pm 11.01$ treatments, respectively. The NRS decreased from $7.30 \pm 0.94$ to $3.52 \pm 1.41$, with an improvement score of $1.86 \pm 0.60$. In the acute phase (within 1 week- 1 month), the mean treatment duration and number of treatments were $41.89 \pm 46.72$ days and $11.00 \pm 8.99$ treatments, respectively. The NRS decreased from $7.37 \pm 1.02$ to $3.78 \pm$ 1.37 , with an improvement score of $1.94 \pm 0.64$. In the subacute stages (1-6 months after onset), the mean treatment duration and number of treatments were $84.79 \pm 80.44$ days and $17.43 \pm$ 12.62, respectively. The NRS decreased from $7.39 \pm 0.81$ to 3.43 \pm 1.10 , with an improvement score of $1.71 \pm 0.45$. Significant differences in mean treatment duration $(\mathrm{p}<0.01)$ and number of treatments $(p<0.01)$ were observed according to the disease duration but not for NRS change and the improvement score (Table 5).

Table 4. Treatment duration, number of treatments, NRS, and improvement score according to demographic characteristics

\begin{tabular}{|c|c|c|c|c|c|c|}
\hline & & $\begin{array}{l}\text { Treatment } \\
\text { duration }\end{array}$ & $\begin{array}{l}\text { Number of } \\
\text { treatments }\end{array}$ & Initial NRS & Posttreatment NRS & $\begin{array}{c}\text { Symptom } \\
\text { improvement }\end{array}$ \\
\hline \multirow[t]{2}{*}{ Sex } & Male $(n=209)$ & $32.90 \pm 35.09$ & $10.62 \pm 9.05$ & $7.27 \pm 0.94$ & $3.53 \pm 1.45$ & $1.84 \pm 0.63$ \\
\hline & p-value & $0.000 * *$ & $0.008 * *$ & 0.740 & 0.173 & $0.032 *$ \\
\hline \multirow[t]{5}{*}{ Age (years) } & $<30(n=72)$ & $42.92 \pm 60.84$ & $11.43 \pm 11.92$ & $7.31 \pm 0.97$ & $3.49 \pm 1.45$ & $1.81 \pm 0.54$ \\
\hline & $40 \leq,<50(n=79)$ & $37.67 \pm 38.87$ & $11.99 \pm 9.08$ & $7.37 \pm 1.04$ & $3.34 \pm 1.25$ & $1.84 \pm 0.64$ \\
\hline & $50 \leq,<60(n=36)$ & $50.25 \pm 47.59$ & $16.83 \pm 14.28$ & $7.44 \pm 0.80$ & $3.21 \pm 1.18$ & $1.72 \pm 0.56$ \\
\hline & $60 \leq(n=18)$ & $51.11 \pm 57.85$ & $15.44 \pm 10.65$ & $7.42 \pm 0.89$ & $3.61 \pm 1.46$ & $1.94 \pm 0.62$ \\
\hline & $p$-value & $0.001 * *$ & $0.004 * *$ & 0.798 & 0.333 & 0.823 \\
\hline All $(n=342)$ & & $37.68 \pm 45.11$ & $11.68 \pm 10.63$ & $7.32 \pm 0.96$ & $3.57 \pm 1.40$ & $1.87 \pm 0.61$ \\
\hline
\end{tabular}

Values are mean \pm SD. Statistical analyses were performed using independent two-sample t-tests or analysis of variance (ANOVA). ${ }^{*}<0.05$ and $* * p<0.01$.

NRS, numerical rating scale. 
Table 5. Treatment duration, number of treatments, NRS, and improvement score according to disease duration and traffic accident characteristics

\begin{tabular}{|c|c|c|c|c|c|c|}
\hline & & $\begin{array}{l}\text { Treatment } \\
\text { duration }\end{array}$ & $\begin{array}{l}\text { Number of } \\
\text { treatments }\end{array}$ & Initial NRS & $\begin{array}{c}\text { Posttreatment } \\
\text { NRS }\end{array}$ & $\begin{array}{c}\text { Symptom } \\
\text { improvement }\end{array}$ \\
\hline & & \multicolumn{5}{|c|}{ Mean \pm SD } \\
\hline \multirow[t]{4}{*}{ Disease duration } & Within 1 week $(n=242)$ & $33.49 \pm 40.23$ & $11.58 \pm 11.01$ & $7.30 \pm 0.94$ & $3.51 \pm 1.41$ & $1.86 \pm 0.60$ \\
\hline & Acute stage $(n=87)$ & $41.89 \pm 46.72$ & $11.00 \pm 8.99$ & $7.37 \pm 1.02$ & $3.78 \pm 1.37$ & $1.94 \pm 0.64$ \\
\hline & Subacute stage $(n=13)$ & $84.79 \pm 80.44$ & $17.43 \pm 12.62$ & $7.39 \pm 0.81$ & $3.43 \pm 1.10$ & $1.71 \pm 0.45$ \\
\hline & p-value & $0.001 * *$ & $0.004 * *$ & 0.902 & 0.957 & 0.852 \\
\hline \multicolumn{7}{|l|}{ Traffic accident situation } \\
\hline \multirow[t]{8}{*}{ Traffic accident patterns } & Rear impact $(n=218)$ & $35.73 \pm 38.40$ & $11.73 \pm 10.54$ & $7.28 \pm 0.97$ & $3.52 \pm 1.32$ & $1.85 \pm 0.57$ \\
\hline & Frontal impact $(n=14)$ & $29.50 \pm 29.81$ & $10.21 \pm 6.90$ & $7.25 \pm 0.87$ & $3.5 \pm 1.41$ & $1.86 \pm 0.83$ \\
\hline & Side impact $(n=36)$ & $26.31 \pm 22.84$ & $8.08 \pm 5.51$ & $7.38 \pm 0.85$ & $3.64 \pm 1.52$ & $1.86 \pm 0.63$ \\
\hline & Multiple impact $(n=18)$ & $25.83 \pm 24.46$ & $8.11 \pm 5.87$ & $7.56 \pm 0.90$ & $4.47 \pm 1.65$ & $2.11 \pm 0.57$ \\
\hline & Pedestrian $(n=23)$ & $97.57 \pm 94.88$ & $21.61 \pm 16.55$ & $7.63 \pm 0.85$ & $3.24 \pm 1.20$ & $1.70 \pm 0.55$ \\
\hline & Motorbike, bicycle, others $(n=27)$ & $25.85 \pm 25.97$ & $9.63 \pm 6.67$ & $7.06 \pm 0.95$ & $3.69 \pm 1.5$ & $1.96 \pm 0.69$ \\
\hline & On the bus $(n=6)$ & $55.17 \pm 68.40$ & $17.00 \pm 19.03$ & $7.33 \pm 1.18$ & $3.5 \pm 1.04$ & $2 \pm 0.58$ \\
\hline & $p$-value & 0.070 & 0.347 & 0.296 & 0.276 & 0.665 \\
\hline \multirow[t]{7}{*}{ Location } & Driver $(n=257)$ & $34.26 \pm 35.77$ & $11.25 \pm 9.92$ & $7.33 \pm 0.95$ & $3.61 \pm 1.42$ & $1.89 \pm 0.61$ \\
\hline & Passenger $(n=17)$ & $23.65 \pm 14.12$ & $7.35 \pm 4.90$ & $7.50 \pm 0.87$ & $3.71 \pm 1.48$ & $1.82 \pm 0.53$ \\
\hline & Back $(n=12)$ & $25.00 \pm 31.80$ & $7.92 \pm 5.71$ & $7.04 \pm 1.12$ & $3.38 \pm 0.88$ & $1.67 \pm 0.49$ \\
\hline & Pedestrian $(n=23)$ & $97.57 \pm 94.88$ & $21.61 \pm 16.55$ & $7.63 \pm 0.85$ & $3.24 \pm 1.20$ & $1.70 \pm 0.55$ \\
\hline & Motorbike, bicycle, others $(n=27)$ & $25.85 \pm 25.97$ & $9.63 \pm 6.67$ & $7.06 \pm 0.95$ & $3.69 \pm 1.5$ & $1.96 \pm 0.69$ \\
\hline & Bus $(n=6)$ & $55.17 \pm 68.40$ & $17.00 \pm 19.03$ & $7.33 \pm 1.18$ & $3.5 \pm 1.04$ & $2 \pm 0.58$ \\
\hline & $p$-value & $0.004 * *$ & $0.034 *$ & 0.238 & 0.843 & 0.542 \\
\hline
\end{tabular}

Values are mean \pm SD. Statistical analyses were performed using analysis of variance (ANOVA). ${ }^{*} p<0.05$ and $* * p<0.01$.

NRS, numerical rating scale.

\section{4) Treatment results according to traffic accident characteristics}

Among the accident types, the mean treatment duration and number of treatments in rear collision were $35.73 \pm 38.40$ days and $11.73 \pm 10.54$ treatments, respectively. The NRS decreased from $7.28 \pm 0.97$ to $3.52 \pm 1.32$, with an improvement score of $1.85 \pm 0.57$. For forward collisions, the mean treatment duration and number of treatments were $29.50 \pm 29.81$ days and $10.21 \pm 6.90$ treatments, respectively. The NRS decreased from $7.25 \pm 0.87$ to $3.5 \pm 1.41$, with an improvement score of 1.86 \pm 0.83 . For lateral collision, the mean treatment duration and number of treatments were $26.31 \pm 22.84$ days and $8.08 \pm 5.51$, respectively. The NRS decreased from $7.38 \pm 0.85$ to $3.64 \pm 1.52$, with an improvement score of $1.86 \pm 0.63$. For multi-collision, the mean treatment duration and number of treatments were $97.57 \pm 94.88$ days and $21.61 \pm 16.55$ treatments, respectively. The NRS decreased from $7.56 \pm 0.90$ to $4.47 \pm 1.65$, with an improvement score of $2.11 \pm 0.57$. For pedestrian accidents, the mean treatment duration and number of treatments were $33.49 \pm 40.23$ days and $11.58 \pm 11.01$, respectively. The NRS decreased from $7.63 \pm 0.85$ to $3.24 \pm 1.20$, with an improvement score of $1.70 \pm 0.55$. For vehicle and motorcycle accidents, the mean treatment duration and number of treatments were 25.85 \pm 25.97 days and $9.63 \pm 6.67$ treatments, respectively. The NRS decreased from $7.06 \pm 0.95$ to $3.69 \pm 1.53$, with an improvement score of $1.96 \pm 0.69$. For bus passengers, the mean treatment duration and number of treatments were $55.17 \pm 68.40$ days, and $17.00 \pm 19.03$, respectively. The NRS decreased from 7.33 \pm 1.18 to $3.5 \pm 1.04$, with an improvement score of $2 \pm 0.58$. No significant differences were observed in treatment duration, number of treatments, NRS before and after treatment, or improvement according to the accident type.

Among locations at the time of the accident, the mean treatment duration and number of treatments were $34.26 \pm 35.77$ 
days and $11.25 \pm 9.92$ treatments, respectively, for the driver seat. The NRS decreased from $7.33 \pm 0.95$ to $3.61 \pm 1.42$, with an improvement score of $1.89 \pm 0.61$. For the passenger seat, the mean treatment duration and number of treatments were 23.65 \pm 14.12 days and $7.35 \pm 4.90$ treatments, respectively. The NRS decreased from $7.50 \pm 0.87$ to $3.71 \pm 1.48$, with an improvement score of $1.82 \pm 0.53$. For the rear seat, the mean treatment duration and number of treatments were $25.00 \pm 31.80$ days and 7.92 \pm 5.71 , respectively. The NRS decreased from $7.04 \pm 1.12$ to 3.38 \pm 0.88 , with an improvement score of $1.67 \pm 0.49$. Significant differences were observed in treatment duration $(p<0.01)$ and number of treatments $(\mathrm{p}<0.01)$ according to the location at the time of the accident, but not for NRS before and after treatment or improvement score (Table 5).

\section{5) Treatment results according to the presence of symptoms} other than pain and psychological symptoms

In the presence of additional symptoms, the mean treatment duration and number of treatments were $40.24 \pm 48.57$ days and $12.51 \pm 11.62$, respectively. The NRS decreased from $7.34 \pm$ 1.01 to $3.53 \pm 1.36$, with an improvement score of $1.87 \pm 0.61$. In the absence of additional symptoms, the mean treatment duration and number of treatments were $29.69 \pm 31.30$ days and $9.07 \pm 6.13$, respectively. The NRS decreased from $7.24 \pm$ 0.75 to $3.72 \pm 1.50$, with an improvement score of $1.95 \pm 0.66$. Significant differences were observed for treatment duration $(\mathrm{p}$ $<0.05)$, number of treatments $(\mathrm{p}<0.05)$, and pre $(\mathrm{p}<0.01)$ and post-treatment NRS $(\mathrm{p}<0.05)$.
The average treatment duration and number of treatments in patients with psychological symptoms, were $44.74 \pm 58.72$ days and $14.28 \pm 14.74$ treatments, respectively. The NRS decreased from $7.34 \pm 1.01$ to $3.53 \pm 1.36$, with an improvement score of. $1.87 \pm 0.61$. In the absence of psychological symptoms, the mean treatment duration and number of treatments were $35.72 \pm 40.58$ days and $10.96 \pm 9.11$ treatments, respectively. The initial NRS decreased from $7.24 \pm 0.75$ to $3.72 \pm 1.50$, with an improvement score of $1.95 \pm 0.66$. Significant differences in treatment duration $(\mathrm{p}<0.05)$ and number of treatments $(\mathrm{p}<$ 0.01 ) were observed according to the presence of psychological symptoms but not for NRS and improvement score (Table 6).

\section{6) Chuna treatment results}

The mean duration and number of chuna treatments were $54.58 \pm 50.25$ days and $17.84 \pm 11.80$, respectively. The NRS decreased from $7.67 \pm 0.91$ to $3.21 \pm 1.10$, with an improvement score of $1.71 \pm 0.55$. In cases without chuna treatment, the mean treatment duration and number of treatments were 23.25 \pm 34.62 days and $6.38 \pm 5.52$, respectively. The NRS decreased from $7.01 \pm 0.89$ to $3.89 \pm 1.54$, with an improvement score of $2.01 \pm 0.62$. No significant difference in NRS was observed before treatment; however, significant differences were observed in treatment duration $(\mathrm{p}<0.01)$, number of treatments $(\mathrm{p}<$ $0.01)$, post-treatment NRS ( $\mathrm{p}<0.01)$, and improvement score $(\mathrm{p}$ $<0.05$ ) (Table 6).

Table 6. Treatment duration and number, NRS, and improvement according to additional symptoms, psychological symptoms, and chuna

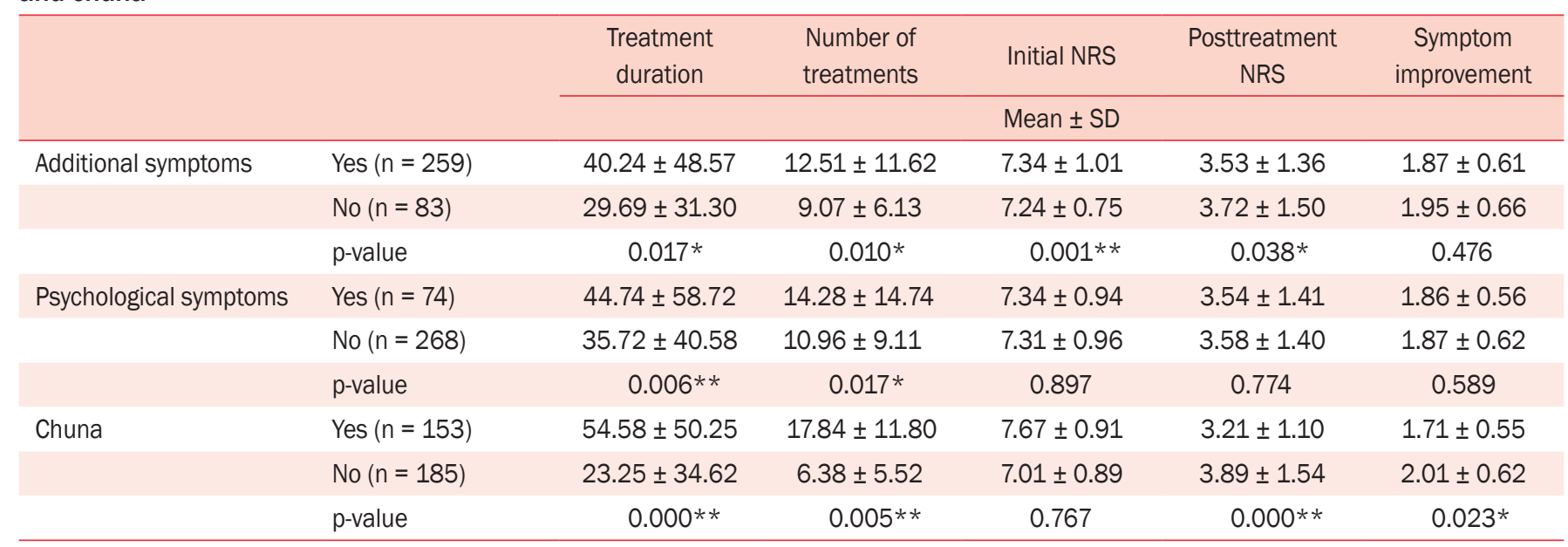

Values are mean \pm SD. Statistical analyses were performed using the independent two-sample t-tests. ${ }^{*} p<0.05$ and ${ }^{* *} p<0.01$. NRS, numerical rating scale. 
7) Treatment results according to the treatment number and duration

Analysis of the number of treatments showed an NRS decrease from $7.01 \pm 0.90$ to $3.91 \pm 1.55$ and an improvement score of $2.02 \pm 0.63$ for 10 or fewer treatments. For 20 or fewer treatments, the NRS decreased from $7.7 \pm 0.84$ to $3.13 \pm 0.93$, with an improvement score of $1.72 \pm 0.45$. For 30 or fewer treatments, the NRS decreased from $7.83 \pm 0.81$ to $2.89 \pm 0.93$, with an improvement score of $1.44 \pm 0.50$. Finally, for more than 30 treatments, the NRS decreased from $8.02 \pm 0.85$ to $3.10 \pm 0.92$, with an improvement score of $1.57 \pm 0.49$. Significant differences were observed in initial NRS ( $\mathrm{p}<0.01)$, and improvement score $(\mathrm{p}<0.05)$.

Analysis of the treatment period showed that NRS decreased from $7.07 \pm 0.90$ to $3.81 \pm 1.53$, with an improvement score of $1.96 \pm 0.64$ within one month. Within 2 months, the NRS decreased from $7.59 \pm 0.85$ to $3.12 \pm 1.06$, with an improvement score of $1.76 \pm 0.52$. Within 3 months, the NRS decreased from $8 \pm 0.80$ to $3.43 \pm 1.00$, with an improvement score of $1.76 \pm$ 0.43 . Within 4 months, the NRS decreased from $8.05 \pm 0.93$ to $2.7 \pm 0.6$, with an improvement score of $1.3 \pm 0.46$. Finally, for more than 4 months, the NRS decreased from $7.81 \pm 0.99$ to 3.11 \pm 0.72 , with an improvement score of $1.67 \pm 0.47$. Significant difference in NRS was observed before treatment $(\mathrm{p}<0.01)$; however, no significant differences were observed in posttreatment NRS and improvement score (Table 7).

\section{8) Correlations between the treatment number and duration, NRS before and after treatment, and improvement score}

The treatment number and duration were significantly positively correlated with initial NRS (both $\mathrm{p}<0.001$ ) and significantly negatively correlated with post-treatment NRS ( $\mathrm{p}<0.001$, $\mathrm{p}<0.001$ ) and improvement score (both $\mathrm{p}<0.001$ ). The higher the number of treatments and the longer the treatment duration, the higher the initial NRS, lower the post-treatment NRS, and the better the improvement score (Table 8).

\section{9) Pharmacopuncture use}

A total of 340 patients received pharmacopuncture. In December 2017, TA pharmacopuncture was developed to treat traffic accident patients. We investigated the use of pharmacopuncture. Before the introduction of TA pharmacopuncture, 10 (7.81\%), 49 (38.28\%), and 69 cases (53.91\%) received one,

Table 7. NRS, and improvement score according to treatment duration and number of treatments

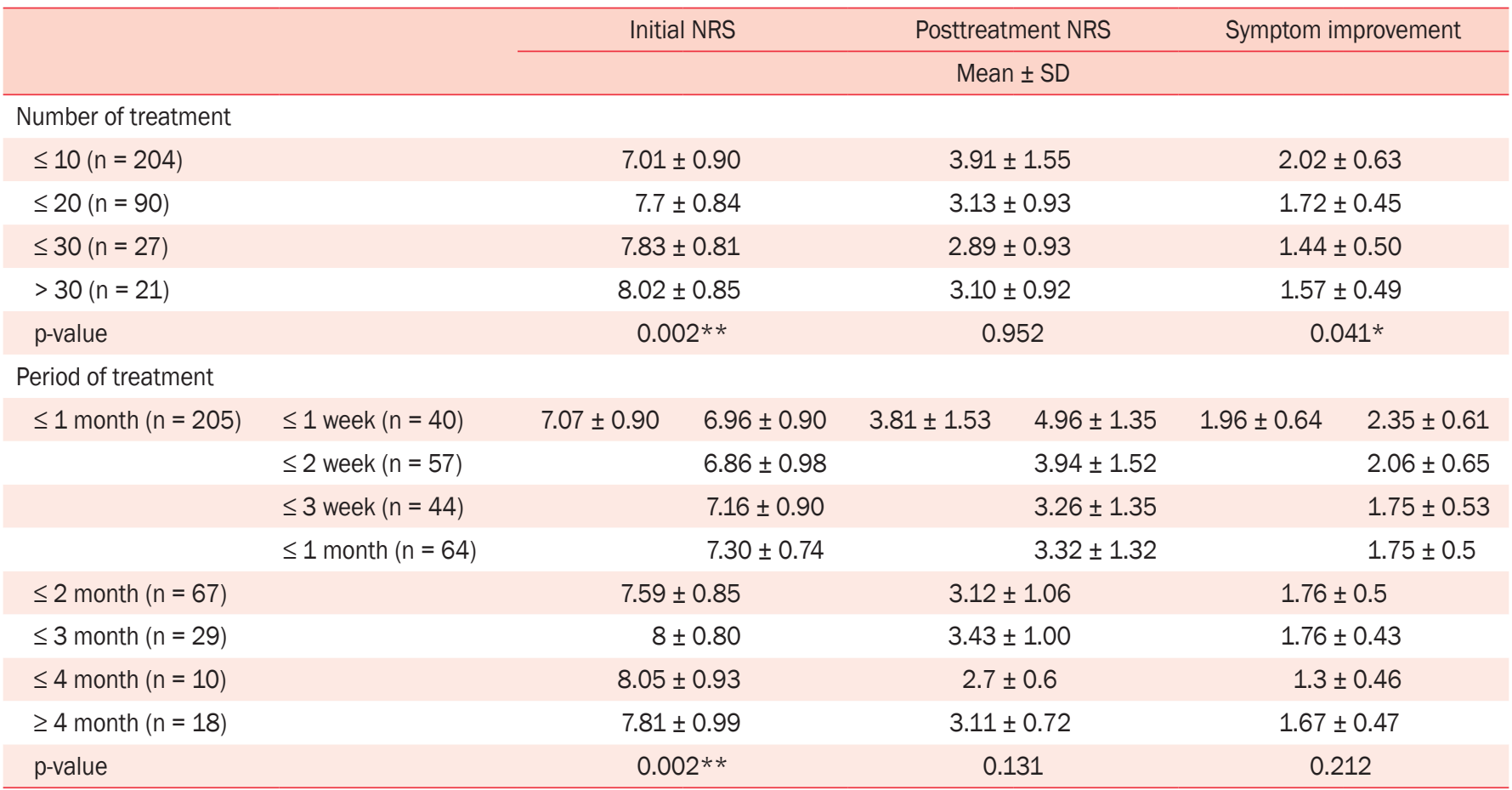

Values are mean \pm SD. Statistical analyses were performed using analysis of variance (ANOVA). ${ }^{*} p<0.05$ and $* * p<0.01$.

NRS, numerical rating scale. 
Jin-Ho Jeong, et al.

Table 8. Correlation analysis between treatment period and number, NRS, and improvement

\begin{tabular}{lccccc}
\hline & Number of treatments & Treatment period & Initial NRS & Post-treatment NRS & Symptom improvement \\
\cline { 2 - 5 } & & & $r(p)$ & & \\
\hline Number of treatments & 1 & $0.815 * *(0.000)$ & $0.304 * *(0.000)$ & $-0.205 * *(0.000)$ & $-0.216 * *(0.000)$ \\
Treatment period & & 1 & $0.353 * *(0.000)$ & $-0.290 * *(0.000)$ & $-0.308 * *(0.000)$ \\
Initial NRS & & 1 & $0.154 * *(0.004)$ & $-0.140 * *(0.010)$ \\
Posttreatment NRS & & & 1 & $0.764 * *(0.000)$ \\
Symptom improvement & & & 1 \\
\hline
\end{tabular}

Statistical significance was evaluated by Pearson's correlation analysis.

r: correlation. p: p-value. $* * p<0.01$.

NRS, numerical rating scale.

Table 9. Use of main pharmacopuncture methods

\begin{tabular}{|c|c|c|c|c|c|c|c|}
\hline \multirow{2}{*}{\multicolumn{3}{|c|}{$\begin{array}{l}\text { Total number of pharmacopuncture types } \\
\text { used for treatment }\end{array}$}} & $\begin{array}{l}\text { Treatment period } \\
\text { (days) }\end{array}$ & $\begin{array}{l}\text { Number of } \\
\text { treatments }\end{array}$ & Initial NRS & $\begin{array}{l}\text { Post-treatment } \\
\text { NRS }\end{array}$ & $\begin{array}{l}\text { Symptom } \\
\text { improvemen }\end{array}$ \\
\hline & & & \multicolumn{5}{|c|}{ Mean \pm SD } \\
\hline \multirow[t]{9}{*}{ Using TA } & Before $(n=128)$ & $1(n=10)$ & $39.70 \pm 45.60$ & $7.50 \pm 6.62$ & $7.15 \pm 0.85$ & $3.90 \pm 1.76$ & $2.00 \pm 0.82$ \\
\hline & & $2(n=49)$ & $40.43 \pm 59.38$ & $12.06 \pm 12.83$ & $7.41 \pm 0.98$ & $3.67 \pm 1.54$ & $1.90 \pm 0.65$ \\
\hline & & 3 or more $(n=69)$ & $36.35 \pm 44.87$ & $10.97 \pm 8.81$ & $7.22 \pm 0.97$ & $3.38 \pm 1.28$ & $1.81 \pm 0.60$ \\
\hline & & & $38.17 \pm 50.62$ & $11.15 \pm 10.39$ & $7.32 \pm 0.97$ & $3.54 \pm 1.42$ & $1.85 \pm 0.63$ \\
\hline & $\operatorname{After}(n=212)$ & $1(n=116)$ & $26.26 \pm 29.46$ & $8.46 \pm 7.14$ & $7.12 \pm 0.92$ & $3.79 \pm 1.43$ & $1.99 \pm 1.67$ \\
\hline & & $2(n=60)$ & $45.05 \pm 54.71$ & $14.10 \pm 12.51$ & $7.51 \pm 1.01$ & $3.14 \pm 1.24$ & $1.67 \pm 0.51$ \\
\hline & & 3 or more $(n=36)$ & $61.03 \pm 39.85$ & $20.08 \pm 12.66$ & $7.74 \pm 0.78$ & $3.68 \pm 1.35$ & $1.83 \pm 0.51$ \\
\hline & & & $37.48 \pm 41.87$ & $12.01 \pm 10.85$ & $7.32 \pm 0.95$ & $3.59 \pm 1.39$ & $1.88 \pm 0.56$ \\
\hline & $p$-value & & 0.325 & 0.331 & 0.524 & 0.843 & 0.337 \\
\hline \multicolumn{3}{|c|}{ Total $(n=340)$} & $37.74 \pm 45.29$ & $11.69 \pm 10.67$ & $7.32 \pm 0.96$ & $3.57 \pm 1.40$ & $1.87 \pm 0.61$ \\
\hline
\end{tabular}

Values are mean \pm SD. Statistical analyses were performed using independent two-sample t-tests. $* p<0.05$ and $* * p<0.01$.

TA: a pharmacopuncture extract named for traffic accidents consisting of Scutellaria baicalensis, Phellodendron amurense, Pulsatilla koreana, Sophora tonkinensis, Aucklandia lappa, Aquilaria agallocha, and Carthamus tinctorius L.

NRS, numerical rating scale.

two, or three or more types of acupuncture, respectively. After the introduction of TA pharmacopuncture, 116 (54.72\%), 60 $(28.30 \%)$, and $36(16.98 \%)$ cases received one, two, or three or more types of acupuncture, respectively. Since the introduction of TA pharmacopuncture, the rate of use of one type of pharmacopuncture increased from $7.81 \%$ to $54.72 \%$. Before using TA pharmacopuncture, the mean treatment duration and number of treatments were $38.17 \pm 50.62$ days and $11.15 \pm$ 10.39, respectively; the NRS decreased from $7.32 \pm 0.97$ to 3.54 \pm 1.42 , with and an improvement score of $1.85 \pm 0.63$. After the introduction of TA pharmacopuncture, the treatment duration and number of treatments were $37.48 \pm 41.87$ days and $12.01 \pm$ 10.85, respectively; the NRS decreased from $7.32 \pm 0.95$ to 3.59 \pm 1.3 , with an improvement score of $1.88 \pm 0.56$. No significant differences were observed between treatment groups before and after TA pharmacopuncture in treatment duration and number, NRS before and after treatment, and improvement score (Table 9).

\section{0) Therapeutic and adverse events}

No adverse reactions including infection, bleeding, hematoma, fatigue, sweating, severe nausea, dizziness, and headache, were observed for any treatment. Sixteen cases of pain, 16 cases of body ache, 10 cases of tingling feelings, and one case of tingling skin were reported during treatment. The treatment rejections included three pharmacopuncture treatment rejections, one $\mathrm{CP}$ pharmacopuncture medicine rejection, one electroacupuncture treatment rejection, and one rejection for all kinds 
of needle treatment.

\section{DISCUSSION}

Traffic accidents are a social problem that poses a serious threat to people's lives, causing pain and mental anguish for the victims and their families. Furthermore, the number of traffic accident patients and medical expenses are rising due to increased automobile use. The number of patients visiting $\mathrm{KM}$ institutions is constantly increasing due to $\mathrm{KM}$ automobile insurance coverage and patient satisfaction for the treatment of traffic accidents; moreover, to compensate for the lack of treatment in WM institutions, traffic accident patients often chose KM treatment such as acupuncture, herbal medicine, chuna, and pharmacopuncture, and they experience satisfaction after treatment and showed self-diffusion and ambient diffusion for KM treatment $[8,12]$. Various domestic and international clinical and experimental studies have assessed the effects of KM treatment for treating traffic accident injury syndrome, and more patients are expected to use KM treatment in the future $[12,13]$. However, there are few reports related to automobile insurance care at KM clinics, which was ranked first among medical billing by type of medical institution [9]; thus, there is a need to determine the medical status at KM Clinics. Therefore, this study investigated the medical status of 342 traffic accident patients who visited the Jisung Kyunghee KM clinic between January 1, 2017, and June 30, 2019.

Of the 342 patients, 209 (61.11\%) were men and 138 (38.99\%) were women, with men 1.51 times more predominant than women. This finding differed from those of previous reports of more female patients in car accidents in Korea [7, 8]. One explanation for this difference may be the many opportunities for treatment of male patients in the present study because our clinic is located in a city with many floating populations. In terms of age distribution, patients in their 30s and 40s accounted for about $63 \%$ of the patient population and patients in their 20 s-50s accounted for about $95 \%$ of the total. This finding is concordant with that of previous reports suggesting the greatest risk of traffic accidents in the age groups which is the main cause of social activity [11], in which there are not only many drivers in the younger age groups but also concern regarding the aftermath of traffic accidents. No significant differences in NRS before and after treatment or improvement score was observed according to sex and age, but a statistically significant difference was observed for treatment duration and number of treatments. The significantly higher treatment period and number of treatments in women compared to those in men may be linked to the results of previous studies reporting that women have a lower employment rate than men, have more time for treatment, and are more susceptible to trauma and the aftereffects of traffic accidents $[14,15]$.

The treatment period and number of treatments were lowest in patients in their 30s and were lower for patients in their 20s and 40s than for those in their 50s or older. This finding may be related to previous reports that young people are relatively active in seeking treatment because of their high level of awareness and concern about the aftereffects of car accidents, with high treatment effects in the younger individuals, while middleaged people in their 50s and 60s and elderly people in their $80 \mathrm{~s}$ are less resilient to the aftereffects of car accidents [16].

Previous studies on traffic accident types observed many minor injuries due to being in the driver seat and rear collision among patients receiving $\mathrm{KM}$ treatment $[7,8]$. In the present study, rear collisions $(218,63.74 \%)$ and driver seats $(257$, $75.15 \%)$ were also the most common factors. There were no statistically significant differences in treatment duration and number, NRS before and after treatment, improvement score according to accident type or in NRS before and after treatment, and improvement score according to the location at the time of the accident. In terms of the treatment period and number of treatments according to the location at the time of the accident, the treatment period was significantly longer and the number of treatments were higher in the order of pedestrian, bus passenger, driver seat, motorcycle or bicycle, back seat, and passenger seat, likely because a pedestrian experienced the greatest impact of a direct collision.

The main disease codes of traffic accident patients visiting $\mathrm{KM}$ institutions were sprains and strains of the c-spine (S13, $56.3 \%)$, sprains and strains of the lumbar and pelvic region (S33, 25.7\%), and intracranial injury (S06, 8.0\%) $[3,16,17]$ accompanied by localized pain in various areas and systemic and mental symptoms $[6,9,18-20]$. The present study also observed various systemic and psychological symptoms, and all patients had localized pain. Meanwhile, pain around the lumbar and pelvic region and cervical spine and shoulders were observed in that order. For most cases with combined neck and shoulder muscle soreness, our clinic used code S43.4 (sprain and strain of the shoulder joint); therefore, the main disease code differed slightly from that in the previous report. In cases with additional symptoms and mental symptoms other than pain, the treat- 
ment duration and number were significantly longer; moreover, the NRS before treatment was larger in patients with additional symptoms. Therefore, the presence of symptoms other than pain may predict treatment duration and frequency.

Previous studies reported that most accidents on roads are minor [21]. Most patients who visit KM institutions are diagnosed with simple sprains owing to the characteristics of KM treatment that the primary care in WM hospitals excludes serious damage because that the more severe the pain after a traffic accident, the more often the first visit to WM hospital is chose $[6,8]$. In our study, 134 patients (39.18\%) visited our clinic first following a traffic accident, a finding likely to be the result of simple sprain in patients with minor accidents based on previous reports. Before coming to our clinic, 106 patients (30.99\%) had been treated and tested at WM institutions and 52 (15.20\%) were only tested at WM institutions, a finding consistent with those of a survey on KM use and herbal medicine consumption in 2017, in which $50.4 \%$ of KM outpatients first presented to other medical institutions, mainly WM clinics (55.4\%), for treatment of the same symptoms. In previous studies, most traffic accident patients who visited KM institutions first presented to WM hospitals, which was attributed to psychological factors of the victims and perpetrators who preferred WM examination even though their symptoms were minor $[6,9]$. The perspectives of these previous studies can be applied in the present study.

Regarding the motivation for selecting our clinic, $197 \mathrm{pa}-$ tients $(57.60 \%)$ visited through an internet search, 70 were existing patients (20.47\%), 36 (10.53\%) visited due to acquaintance introduction, 35 (10.23\%) visited due to proximity, and four (1.17\%) patients selected our clinic for other reasons. A survey on KM use and herbal medicine consumption in 2017 reported that $34.9 \%$ of Koreans reported being aware of KM care and that information or knowledge on KM care were most commonly obtained from neighbors such as family and friends (38.6\%), followed by broadcasting media (27.3\%) and KM institutions (24.9\%) [22]. Internet searches were likely the main motive for visiting our clinic because the market for KM automobile insurance has grown recently, and patients reportedly have high awareness and satisfaction with KM automobile insurance care [8]. Moreover, KM institutions are actively promoting and providing information, including in networks related to traffic accidents.

Regarding the duration of disease before presenting to our clinic, most patients $(242,70.76 \%)$ reported during the acute phase (within 1 week), and patients with acute and subacute phases had passed through other medical institutions during the most acute phase. Most patients likely visited medical institutions during the most acute phase because both the victim and offender felt the need for prompt treatment due to mental shock and discomfort in daily life immediately after the accident, in addition to psychological factors associated with compensation issues with auto insurance companies. No significant difference in NRS before and after treatment and improvement score according to the duration of disease were observed; however, a longer disease duration was associated with a longer treatment duration and higher number of treatments. Prospective studies have reported that most recoveries occur up to 3 months after the initial injury $[23,24]$; thus, appropriate care management is important in the acute and subacute stages to prevent the development of chronic diseases [18]. To prevent the disease from becoming chronic, treatment should be started soon after the traffic accident.

Assessment of the distribution of treatment period showed that the majority of patients $(218,63.74 \%)$ completed treatment within 1 month, a finding concordant with those of previous reports from KM institutions that treatment rarely lasts for more than 1 month [9]. The average number of treatments was $11.68 \pm 10.63 ; 204(59.65 \%)$ and $90(16.67 \%)$ patients received fewer than 10 and 20 treatments, respectively. This is consistent with a report indicating an average of 11.6 outpatient visits to $\mathrm{KM}$ in the past year in a survey of KM use and herbal medicine consumption in 2017 [22]. Furthermore, considering the treatment period, the number of treatments was not high because most patients could not attend daily due to social activities. The initial NRS of all patients, $7.32 \pm 0.96$, decreased to $3.57 \pm 1.40$ at the end of treatment; the improvement score, $1.87 \pm 0.60$, was between (1) Excellent and (2) Good. Analysis of the correlation between treatment duration and number, NRS change, and improvement score showed that the higher the number of treatments and the longer treatment duration, the higher the initial NRS, the lower the NRS after treatment, and the better the improvement score. This finding was related to that of a previous report demonstrating that the recovery rate was not constant in cases of prolonged treatment and depended on the degree of injury; furthermore, recovery was delayed due to social activities or labor during outpatient treatment [6]. Furthermore, this is thought to be an extension of the treatment period due to the severity of the treatment, rather than long-term treatment because the treatment effect is weak, given the NRS change and 
improvement scores.

Pharmacopuncture is a new acupuncture treatment combining acupuncture and herbal medicines that has been used for almost all types of diseases in KM clinical practice and is the second-most common treatment after acupuncture in traffic accident patients $[8,16]$. In particular, $\mathrm{HO}, \mathrm{HN}, \mathrm{V}, \mathrm{OK}$, and TA are used to treat acute or chronic inflammation and pain in patients with musculoskeletal disorders and traffic accident injury syndrome [25-27]. In our clinic, $99.42 \%$ of patients were administered pharmacopuncture in the order of $\mathrm{TA}, \mathrm{HO}, \mathrm{CH}$, and $\mathrm{MOK}$, and various kinds of acupuncture were used alone or in combination during the treatment period. Chuna was performed when symptoms improved slowly or when additional treatment was needed; therefore, the number of patients treated with chuna (153 patients, $44.74 \%$ ) was smaller than the number of patients receiving pharmacopuncture, and patients treated with chuna had significantly longer treatment periods and higher numbers of treatments.

In our study, TA was the most commonly used pharmacopuncture. The plant-based extract TA was developed in 2015 to replace the animal-based extracts Bovis Calculus-Ursi FelMoschus (BUM or V), for which it was difficult to obtain stable supplies. TN consists of Scutellariae Radix, Phellodendri Cortex, Pulsatillae Radix, Sophorae Tonkinensis Radix et Rhizoma, Aucklandiae Radix, Aquilariae Lignum, and Carthami Fructus and was named for its principal use in treating traffic accidentrelated injuries. TA has been experimentally confirmed to be safe; however, while its clinical use is increasing, there few clinical reports [26-28]. We started using TA pharmacopuncture in December 2017 and changed to a treatment method mainly using TA pharmacopuncture. Since TA acupuncture alone was used in more than $50 \%$ of cases, the variety of types of pharmacopuncture was less than that before TA pharmacopuncture. No statistically significant differences were observed in treatment duration and number, NRS before and after treatment, and improvement scores before and after TA pharmacopuncture, a finding that indicates the validity of the development of TA pharmacopuncture for the management of various symptoms caused by traffic accidents, with similar therapeutic effects in place of the role of various pharmacopuncture. However, additional large-scale TA pharmacopuncture-related clinical studies in traffic accident patients are warranted and, after excluding other treatments, group comparisons of the treatment effect and detailed analysis of this effect according to the pain area and symptoms should be performed.
The results of this study confirmed the high treatment effect of KM treatment under automobile insurance reported previously [6-9]. Significant correlations were also observed based on detailed medical status, which may be used as evidence to justify increased KM care in the auto insurance system. No specific adverse reactions were observed for any of the treatments, as well as no discomfort with sequelae; therefore, the safety of KM treatment for traffic accident patients was confirmed to some extent. This study was limited in that it was conducted at a single KM clinic, treatment satisfaction was not investigated, and the operator and evaluator were not blinded. In addition, due to the characteristics of general KM treatment, in which various treatment methods including acupuncture, pharmacopuncture, herbal medicine, physiotherapy, and chuna treatment are combined, the effects of each treatment method were not assessed. In order to accumulate more evidence on the therapeutic effect of oriental medicine on traffic accident injuries, it will be necessary to verify the effect of each KM treatment method and to compare the treatment effect between various KM treatment methods, and additional studies in other regions and larger, multicenter studies are needed.

\section{CONCLUSION}

This study confirmed the previous findings of a high treatment effect of KM under automobile insurance. We also observed significant correlations based on a detailed medical status, which may explain the increasing use of KM in the automobile insurance system. Additional studies in different regions and with larger and multi-center studies are needed.

\section{CONFLICTS OF INTEREST}

The authors declare that they have no conflicts of interest.

\section{DATA AVAILABILITY}

The data used to support the findings of this study are available from the corresponding author upon request.

\section{AUTHORS' CONTRIBUTIONS}

$\mathrm{JHH}$ performed the data analysis and interpretation of the data. JHJ and JHH contributed to the study concept and design. JHJ conducted the study and data collection. JHH and 
JK performed the data analysis and interpretation of the data. $\mathrm{JHH}$ performed manuscript writing, and $\mathrm{JHH}$ and $\mathrm{JHJ}$ revised manuscript.

\section{ORCID}

Jin-Ho Jeong, https://orcid.org/0000-0002-0598-0314

Jaseung Ku, https://orcid.org/0000-0003-4365-5587

Ji Hye Hwang, https://orcid.org/0000-0002-6304-1972

\section{REFERENCES}

1. Ottosson C, Pettersson H, Johansson SE, Nyrén O, Ponzer S. Recovered? Association between self-perceived recovery and the SF-36 after minor musculoskeletal injuries. Qual Life Res. 2007;16(2):217-26.

2. Department for Transport. RAS 60003: Total Value of Prevention of Reported Accidents by Severity and Cost Element: Great Britain. [Internet]. London: GOV.UK; c2021 [cited 2018 Aug 22]. Available from: https://www.gov.uk/government/statisticaldata-sets/ras60-average-value-of-preventing-road-accidents.

3. KoROAD. Estimation and Assessment of Traffic Accident Incurred Costs in 2016. [Internet]. Wonju: TAAS; c2017 [cited 2018 Aug 22]. Available from: http://taas.koroad.or.kr/web/ bdm/srs/selectStaticalReportsList.do? menuId=WEB_KMP_ IDA_SRS_RTE.

4. Song MY, Jo HG, Sul JU, Kim ST, Bae KJ, Kim TG, et al. Inpatient treatment effect and Minnesota Multiphasic Personality Inventory characteristics of motor vehicle collision injuries in a traditional korean medicine hospital: retrospective chart review. Chin J Integr Med. 2016 Nov 3. doi: 10.1007/s11655-016-27433. Epub ahead of print.

5. Health Insurance Review \& Assessment Service. Automobile Insurance Statistical Data. [Internet]. Wonju: HIRA; c2019 [cited 2020 Dec 31]. Available from: http://www.hira.or.kr/bbsDummy. do?brdBltNo=2312\&brdScnBltNo=4\&pgmid=HIRAA02004501 0000\#none.

6. Park SY, Lee YK, Kim JS, Lim SC, Lee BH, Jung TY, et al. Survey of oriental medical care for traffic accident patients with automobile insurance; 544 cases report. J Korean Acupunct Moxib Soc. 2009;26(3):1-10.

7. Hong S, Park W, Ha S. A real-world accident study on vehicle damage types and occupant injury. Trans Korean Soc Automot Eng. 2013;21(1):107-12.

8. Kim HR, Kim SH, Lee YS, Sung WS, Park SH, Cho HS, et al. Survey on satisfaction and symptom improvement of Korean medicine treatment in 122 cases by traffic accident. J Korean
Med. 2018;39(3):61-72.

9. Hwang JH, Jung C. Single-center retrospective study on the status of Korean medicine automobile insurance treatment and usage of main pharmacopuncture. J Physiol Pathol Korean Med. 2019;33(3):181-90.

10. Broekema AE, Molenberg R, Kuijlen JM, Groen RJ, Reneman MF, Soer R. The Odom criteria: validated at last: a clinimetric evaluation in cervical spine surgery. J Bone Joint Surg Am. 2019;101(14):1301-8.

11. Jeon HJ, Kim SH, Kim JH, Lee SM, Shin HY, Lee YK, et al. The clinical study on 197 cases with patients of neck pain caused by traffic accident. J Korean Acupunct Moxib Soc. 2010;27(2):14354.

12. Im SH, Lee SH, Lee SM, Nam DW, Kim YS. A qualitative study on the treatment process experiences of patients with whiplash associated disorder treated with traditional Korean medicine- based on the grounded theory approach. Acupuncture. 2016;33(4):73-92.

13. Moon TW, Posadzki P, Choi TY, Park TY, Kim HJ, Lee MS, et al. Acupuncture for treating whiplash associated disorder: a systematic review of randomised clinical trials. Evid Based Complement Alternat Med. 2014;2014:870271.

14. Kim EG, Lee DG, Jeong WJ, Cho HS, Bae JI, Kim SH, et al. The clinical study on 500 cases with traffic accident patients admitted in oriental medical hospital. J Korean Acupunct Moxib Soc. 2009;26(5):29-38.

15. Kook KH, Oh MS. The analysis of 509 admission patients in Korean medical hospital due to traffic accident. J Korean Med Rehabil. 2012;22(4):169-83.

16. Shin JH, Oh MS. The retrospective analysis of 1,162 traffic accident inpatients in Korean medicine hospital. J Korean Med Rehabil. 2013;23(4):233-50.

17. Song YA, Lee SY The present status and future direction of oriental medical services in the automobile insurance. Seoul: Korea Insurance Research Institute; 2017.

18. Sterling M, Kenardy J. Whiplash: evidence base for clinical practice. Chatswood: Elsevier Australia; 2011.

19. Treleaven J. Dizziness, unsteadiness, visual disturbances, and postural control: implications for the transition to chronic symptoms after a whiplash trauma. Spine (Phila Pa 1976). 2011;36 Suppl 25:S211-7.

20. Kasch H, Turk DC, Jensen TS. Whiplash injury: perspectives on the development of chronic pain. Philadelphia: Wolters Kluwer; 2016.

21. Jung KH, Hwang HS, Jeon JC, Kim MS, Park JY, Lee TH, et al. Correlation analysis of subjective stress caused by traffic accident with prognosis. J Korean Acupunct Moxib Soc. 2009;26(6): 161-9. 
22. NIKOM (National Development Institute of Korean Medicine). Actual situation survey on korean medicine use and herbal medicine consumption. Seoul: National Development Institute of Korean Medicine; 2018.

23. Kamper SJ, Rebbeck TJ, Maher CG, McAuley JH, Sterling M. Course and prognostic factors of whiplash: a systematic review and meta-analysis. Pain. 2008;138(3):617-29.

24. Sterling M, Hendrikz J, Kenardy J. Compensation claim lodgement and health outcome developmental trajectories following whiplash injury: a prospective study. Pain. 2010;150(1):22-8.

25. Korean Acupuncture \& Moxibustion Medicine Society. Acu- puncture medicine. Seoul: Hanmi Medical Publishing Co.; 2016.

26. Hwang JH, Jung HW. TA pharmacopuncture as a primary and independent treatment for frequent sprains occurring over 9 months in a patient with needle sickness: case report. Medicine (Baltimore). 2018;97(45):e13123.

27. Hwang JH, Jung HW, Jung C. Evaluation of the single-dose toxicity of TA pharmacopuncture in rats. J Pharmacopuncture. 2019;22(3):171-5.

28. Chung YJ, Lee YK, Lee HJ, Kim JS. A case report of thoracic pain which was occurred by seat belt with additional TA pharmacopuncture. J Korea Immuno-Yakchim Soc. 2017;6(1):39-48. 